\title{
Secular trends in self reported sexual activity and satisfaction in Swedish 70 year olds: cross sectional survey of four populations, 1971-2001
}

\author{
Nils Beckman, PhD student, Margda Waern, senior lecturer, Deborah Gustafson, senior lecturer, \\ Ingmar Skoog, professor
}

Neuropsychiatric Epidemiology

Unit, Institute of Neuroscience and

Physiology, Sahlgrenska Academy at Gothenburg University,

Gothenburg, Sweden

Correspondence to: $\mathrm{N}$ Beckman, Neuropsychiatric Epidemiology Unit, Neuropsykiatri SU/Mölndal

Wallinsgatan 6, SE 43141 Mölndal nils.beckman@neuro.gu.se

Cite this as: BMJ 2008;337:a279 doi:10.1136/bmj.a279

\section{ABSTRACT}

Objective To study secular trends in self reported sexual behaviour among 70 year olds.

Design Cross sectional survey.

Settings Four samples representative of the general population in Gothenburg, Sweden.

Participants 1506 adults (946 women, 560 men) examined in 1971-2, 1976-7, 1992-3, and 2000-1.

Main outcome measures Sexual intercourse, attitudes to sexuality in later life, sexual dysfunctions, and marital satisfaction.

Results From 1971 to 2000 the proportion of 70 year olds reporting sexual intercourse increased among all groups: married men from $52 \%$ to $68 \%(P=0.002)$, married women from $38 \%$ to $56 \%(P=0.001)$, unmarried men from $30 \%$ to $54 \%(P=0.016)$, and unmarried women from $0.8 \%$ to $12 \%$ $(\mathrm{P}<0.001)$. Men and women from later birth cohorts reported higher satisfaction with sexuality, fewer sexual dysfunctions, and more positive attitudes to sexuality in later life than those from earlier birth cohorts. A larger proportion of men ( $57 \%$ v $40 \%, P<0.001)$ and women $(52 \%$ $\checkmark 35 \%, P<0.001)$ reported very happy relationships in 2000-1 compared with those in 1971-2. Sexual debut before age 20 increased in both sexes: in men from $52 \%$ to $77 \%$ ( $P<0.001)$ and in women from $19 \%$ to $64 \%$ ( $<<0.001)$. Conclusion Self reported quantity and quality of sexual experiences among Swedish 70 year olds has improved over a 30 year period.

\section{INTRODUCTION}

Attitudes to sexuality changed dramatically in Western societies during the 20th century. During that time changing patterns of sexual behaviour were reported in adolescence and young adulthood, such as earlier age of first sexual intercourse. ${ }^{1-3}$ Knowledge about sexual behaviour in elderly people ( 70 year olds) is limited and even less is known about secular trends in sexual behaviour in this age group. Most elderly participants in surveys on sexual behaviour developed their views during the early part of the 20th century and could be expected to have different views from those born later. The Duke longitudinal study, carried out in the 1950s and 1960 s, suggested secular trends in sexual activity among elderly people on the basis of a relatively small number of participants. ${ }^{4}$ A recent study $(2005-6)^{5}$ reported a higher frequency of sexual activity in elderly people than that reported in studies from the mid$1900 \mathrm{~s},{ }^{246-9}$ but the disparity could be due to methodological differences among these studies. We examined secular trends in sexual behaviour (intercourse, age at sexual debut, sexual satisfaction, some sexual dysfunctions) and attitudes to sexuality in later life among four samples representative of the general population of 70 year olds from Gothenburg, Sweden, who were examined using identical methods in 1971-2, 1976-7, 1992-3, and 2000-1.

\section{METHODS}

Sample populations

The multidisciplinary H70 studies (the longitudinal gerontological and geriatric population studies in Gothenburg) started in 1971-2 to study health and health related factors in a sample of 70 year olds from Gothenburg, Sweden. The sample was representative of 70 year olds living in Gothenburg and included those living at home and in institutions. Representative population samples of 70 year olds living in Gothenburg were also surveyed in 1976-7, 1992-3, and 2000-1, to study secular trends in health and health related factors.

The samples were systematically obtained from the Swedish population register, which contains the names and addresses of all Swedish residents. Questions on sexual behaviour were asked during a psychiatric examination. Data from each examination year are cross sectional.

Sample 1-70 year olds born between 1 July 1901 and 30 June 1902 on dates ending with 2, 5, or 8 were invited to a health examination in $1971-2 .{ }^{10}$ The people were numbered consecutively from 1 to 5 . Those with numbers 1 and $2(n=460)$ were invited to take part in a psychiatric examination. Of these, $392(85.2 \%)$ participated (166 men, 226 women). The sample has been described in detail previously. ${ }^{11}$

Sample 2-70 year olds born between 1 July 1906 and 30 June 1907 on dates ending with 2, 5, or 8 were 
invited to a health examination in 1976-7. The selection procedure was the same as for the first sample. Of 513 people invited, 404 (78.8\%) participated in a psychiatric examination (177 men, 227 women). ${ }^{12}$

Sample 3-70 year old women born in 1922 on days 6 , $12,18,24$, or 30 were invited to a health examination in 1992-3. Of 381 women invited for a psychiatric examination, 249 (65.2\%) participated.

Sample 4-70 year olds born in 1930 on days 3, 6, 12, $18,21,24$, or 30 were invited to a health examination in 2000-1. Of 767 invited, $500(65.2 \%)$ participated in the psychiatric examination (229 men, 271 women).

On the basis of information from the Swedish population register responders and non-responders in each of the samples were similar for sex, marital status, and three year mortality rate (table 1 ). Responders and non-responders in the first two samples were further compared for income, municipal rent allowance, previous outpatient or inpatient psychiatric care, and registration with the Temperance Board for alcohol misuse. No significant differences existed between responders and non-responders for these variables. ${ }^{11} 12$ Responders and non-responders in the last two samples were compared for inpatient psychiatric care during the past two years, according to the Swedish hospital discharge register. No differences were found.

Informed consent was obtained from the participants. The general examinations included a home visit by a nurse (first three samples), physical examinations by geriatricians, psychiatric examinations by psychiatrists (psychiatric nurses in last sample), neuropsychological examinations by psychologists, dental examination by dentists, and laboratory tests including electrocardiography, chest radiology, and extensive biochemical evaluations. Information on marital status was obtained from the Swedish population register when comparing participants and non-participants, but in all other analyses these data were self reported.

The semistructured psychiatric examination included assessments of psychiatric symptoms and signs as well as questions on sexual behaviour. Questions were identical at each examination.
Participants were asked about their attitudes to sexuality in later life, frequency of intercourse during the past year, and age of sexual debut and its timing in relation to marriage. Sexual activity was defined as having had intercourse during the past year. Intercourse was defined as sexual contact between individuals, most often with penetration.

Questions asked in the examinations of all but the first sample were about whether sexuality was a positive or negative factor in life, satisfaction with intercourse, sexual dysfunction (including erectile dysfunction, difficulties with ejaculation, premature ejaculation in men, and orgasmic dysfunction in women), and reason for cessation of intercourse.

One of the researchers (IS), a psychiatrist, was trained by those who did the examinations in the $1970 \mathrm{~s}$, and trained those who did the examinations in 1992 and 2000. Inter-rater reliability was investigated among 66 participants who had dual ratings by one researcher (IS) and other examiners. Inter-rater agreement on frequency of intercourse was high between the researcher and examiners in the $1970 \mathrm{~s} \quad(\kappa=0.913$, $\mathrm{P}<0.001)$ and in the $1990 \mathrm{~s}$ and later $(\kappa=0.774$, $\mathrm{P}=0.001)$. Inter-rater agreement on attitudes to sexuality at age 70 was high between the researcher and examiners in the $1970 \mathrm{~s}(\kappa=0.731, \mathrm{P}<0.001)$ and in the $1990 \mathrm{~s}$ and later $(\kappa=0.708, \mathrm{P}<0.001)$.

Diagnoses of dementia and depression were made according to criteria of the Diagnostic and Statistical Manual of Mental Disorder 3rd edition, revised ${ }^{13}$ using algorithms as described previously. ${ }^{14}{ }^{15}$ Dementia was used only as an exclusion criterion. Any depression included major depression, dysthymia, and depression not otherwise specified. The diagnoses were based on symptoms during the month preceding the examination.

\section{Statistical analysis}

We categorised marital status as legally married or cohabiting compared with unmarried (defined as never married, divorced, widowed, and not living with a partner). Educational level was dichotomised as compulsory (six years for those born in 1901-22,

Table 1| Characteristics of 70year olds from Gothenburg, Sweden, participating or not in four cross sectionalsamples surveyed in 1971-2,1976-7,1992-3, and 2000-1. Values are numbers (percentages)

\begin{tabular}{|c|c|c|c|c|c|c|c|c|}
\hline \multirow[b]{3}{*}{ Variable } & \multicolumn{8}{|c|}{ Year of examination } \\
\hline & \multicolumn{2}{|c|}{$1971-2$} & \multicolumn{2}{|c|}{$1976-6$} & \multicolumn{2}{|c|}{1992} & \multicolumn{2}{|r|}{2000} \\
\hline & $\begin{array}{l}\text { Participants } \\
\qquad(n=392)\end{array}$ & $\begin{array}{l}\text { Non-participants } \\
\qquad(\mathrm{n}=68)\end{array}$ & $\begin{array}{l}\text { Participants } \\
(n=404)\end{array}$ & $\begin{array}{l}\text { Non-participants } \\
\quad(n=109)\end{array}$ & $\begin{array}{l}\text { Participants } \\
\qquad(n=249)\end{array}$ & $\begin{array}{l}\text { Non-participants } \\
\qquad(n=132)\end{array}$ & $\begin{array}{l}\text { Participants } \\
\qquad(n=500)\end{array}$ & $\begin{array}{c}\text { Non-participants } \\
(n=267)\end{array}$ \\
\hline Women & $226(58)$ & $41(60)$ & $227(56)$ & $72(61)$ & $249(100)$ & $132(100)$ & $271(54)$ & $127(48)$ \\
\hline \multicolumn{9}{|l|}{ Marital status: } \\
\hline Married & $225(57)$ & $34(50)$ & $230(57)$ & $62(57)$ & $135(54)$ & $56(42)^{\star}$ & $299(60)$ & $139(52)^{\star}$ \\
\hline Widowed & $93(24)$ & $17(25)$ & $101(25)$ & $24(22)$ & $64(26)$ & $34(26)$ & $73(14.6)$ & $38(14)$ \\
\hline Divorced & $16(4)$ & $3(4)$ & $31(8)$ & $10(9)$ & $35(14)$ & $28(21)$ & $99(20)$ & 50 (19) \\
\hline Never married & $58(15)$ & $14(21)$ & $42(10)$ & $13(12)$ & $15(6)$ & $14(11)$ & $29(6)$ & $40(15)^{\star \star \star}$ \\
\hline 3 year mortality & $27(7)$ & $6(9)$ & $25(6)$ & $8(7)$ & $7(3)$ & $5(4)$ & $8(2)$ & $12(5)$ \\
\hline
\end{tabular}

${ }^{*} \mathrm{P}<0.05 ;{ }^{* \star *} \mathrm{P}<0.001$ (Fisher's exact test) for difference in proportions within birth cohorts between participants and non-participants.

†From Swedish population register. 
seven years for those born in 1930) compared with more than compulsory.

Differences in proportions were tested using Fisher's exact test. The Cochran-Armitage $\chi^{2}$ test was used to test for trends. We used an asymptotic permutation test of trend for differences in the median age of sexual debut. Data were analysed by strata of sex and marital status. For regression analyses we also pooled data from all the samples. We used binary logistic regression models to estimate the odds of reporting intercourse (yes or no within the past year) by sample (1971-2 plus 1976-7 v 1992-3 plus 2000-1), marital status, male gender, sexual debut before age 20 , a positive attitude towards sexuality in later life, diagnosis of depression, educational level, and three year mortality. We present the associations as odds ratios and 95\% confidence intervals. In all analyses we used two tailed tests. We considered results significant at $\mathrm{P}<0.05$.

\section{RESULTS}

People with dementia were excluded $(n=39)$. In addition, some participants refused to answer questions on sexuality or were not asked because of language difficulties or because a third party was present during the interview $(\mathrm{n}=69)$.

Table 2 lists the self reported characteristics of the 70 year olds by sample. Among both sexes the proportion of participants who were divorced, cohabiting, or in a relationship but living apart increased over the 30 years from the first sample to the fourth sample. The proportion that were widowed or never married decreased. Among 70 year olds in the later born samples women were more often married or cohabiting. In both sexes the proportion divorced increased during the study period. Among those who had a partner, the proportion reporting a happy relationship increased in both sexes. Compared with men, women in all samples were less often married or cohabiting, more often widowed, and more often had an older partner.

Table 3 shows the responses to questions on sexual behaviour and attitudes in the four samples. The proportion of 70 year olds reporting that they were sexually active, that sexuality had been a positive factor in their life, and that had a positive attitude to sexuality in later life increased during the study period, both among married and cohabiting participants and among unmarried participants. Fewer people in later cohorts reported never having had intercourse. Among those reporting intercourse, the proportion that had intercourse at least once a week increased over the 30 year period. Concurrently the reported median age of sexual debut decreased in both sexes and the proportion reporting premarital intercourse increased in women. Reported intercourse was more common among men than among women in all four samples, and men reported an earlier age of sexual debut than women although the differences between the sexes for this variable diminished among those from later born samples. Prevalence did not change after exclusion of depressed people.

In a logistic regression analysis including the entire sample, being in a later born cohort increased the odds of having intercourse (odds ratio 1.48, 95\% confidence interval 1.10 to 2.00 ), independent of marital status, sex, sexual debut before age 20 , a positive attitude to sexuality in later life, depression, educational level, and three year mortality.

Table 4 shows reported sexual satisfaction and dysfunction among the sexually active participants. The proportion of women reporting high or very high sexual satisfaction increased and reports of no sexual satisfaction decreased from the second sample to the last sample. The proportion of men reporting erectile

Table 2 Self reported characteristics of four samples of 70 year olds from Gothenburg, Sweden, examined in 1971-2, 1976-7, 1992-3, and 2000-1. Values are numbers (percentages) unless stated otherwise

\begin{tabular}{|c|c|c|c|c|c|c|c|c|c|}
\hline \multirow[b]{2}{*}{ Variable } & \multicolumn{4}{|c|}{ Men } & \multicolumn{5}{|c|}{ Women } \\
\hline & $\begin{array}{l}1971-2 \\
(n=161)\end{array}$ & $\begin{array}{l}1976-7 \\
(n=174)\end{array}$ & $\begin{array}{c}2000 \\
(n=225)\end{array}$ & $\begin{array}{l}\text { Sample trend } \\
\text { Pvalue }^{\star}\end{array}$ & $\begin{array}{l}1971-2 \\
(n=221)\end{array}$ & $\begin{array}{l}1976-7 \\
(n=222)\end{array}$ & $\begin{array}{c}1992 \\
(n=241)\end{array}$ & $\begin{array}{c}2000 \\
(n=262)\end{array}$ & $\begin{array}{c}\text { Sample trend } \\
\text { P value* }^{\star}\end{array}$ \\
\hline \multicolumn{10}{|l|}{ Marital status: } \\
\hline Married & $125(78)$ & $132(76)$ & $167(74)$ & 0.469 & $90(41)^{\star \star \star}$ & $92(41)^{\star \star \star}$ & $130(54)$ & $120(46)^{\star \star \star}$ & 0.034 \\
\hline Cohabiting & 0 & $2(1)$ & $14(6)$ & 0 & $2(1)$ & $1(1)$ & $6(3)$ & $13(5)$ & 0 \\
\hline Live apart & 0 & 0 & $12(5)$ & 0 & 0 & 0 & $2(1)$ & $7(3)$ & 0.001 \\
\hline Widowed & $16(10)$ & $19(11)$ & $4(2)$ & 0 & $76(34)^{\star \star \star}$ & $85(38)^{\star \star \star}$ & $61(25)$ & $70(27)^{\star \star \star}$ & 0.002 \\
\hline Divorced & $8(5)$ & $9(5)$ & $24(11)$ & 0.013 & $10(5)$ & $17(8)$ & 34 (14) & $43(16)$ & 0 \\
\hline Never married & $12(7)$ & $12(7)$ & $4(2)$ & 0.004 & $43(20)^{\star \star \star}$ & $27(12)$ & $8(3)$ & $9(3)$ & 0 \\
\hline Happy relationship & $49(40)$ & $35(26)$ & $109(57)$ & 0 & $32(35)$ & $30(32)$ & $69(52)$ & $71(52)$ & 0 \\
\hline Partner $>5$ years younger & $38(31)$ & 26 (19) & $34(18)$ & 0.033 & $5(6) * \star \star$ & $4(4)^{\star \star}$ & - & $5(4) * \star \star$ & 0.864 \\
\hline Partner $>5$ years older & $4(3)$ & $5(4)$ & $12(6)$ & 0.168 & $19(21)^{\star \star \star}$ & $22(24)^{\star \star \star}$ & - & $44(31)^{\star \star \star}$ & 0.058 \\
\hline Mean age of partner (years) & 65.9 & 67.1 & 67.6 & $0.016 \dagger$ & $71.3^{\star \star \star}$ & $71.9^{\star \star \star}$ & - & $72.3^{\star \star \star}$ & $0.215 \dagger$ \\
\hline More than basic education & $25(16)$ & $31(18)$ & $87(43)$ & 0 & 27 (13) & $38(18)$ & $75(38)$ & $91(39)$ & 0 \\
\hline Depression $\ddagger$ & $2(1)$ & $4(2)$ & $8(4)$ & 0.121 & $19(9)$ & $19(9)$ & $26(11)$ & $22(10)$ & 0.585 \\
\hline
\end{tabular}

${ }^{* \star P}<0.01 ;{ }^{* *} \mathrm{P}<0.001$ (Fisher's exact test) for difference between sexes within birth sample.

${ }^{*}$ Cochran-Armitage $x^{2}$ for trends.

†Test for group difference with asymptotic permutation $t$ test.

$\ddagger$ Diagnosed according to Diagnostic and Statistical Manual of Mental Disorders, third edition, revised. 
dysfunction decreased and the proportion with ejaculation dysfunction increased, whereas the proportion reporting premature ejaculation did not change. The proportion of women who reported always or usually having an orgasm during intercourse increased, and the proportion of women reporting never having had an orgasm decreased.

Men reported that the main reason for not having intercourse was due to personal reasons, whereas women reported that it was most often due to partner related factors or lack of a partner (table 5). Among those who had a partner, both sexes reported that in most cases cessation of intercourse was due to male related factors. This pattern did not change over the 30 year period.

\section{DISCUSSION}

Self reported sexual activity among married and unmarried 70 year olds in Gothenburg, Sweden increased from 1971 to 2001. At the same time among elderly people attitudes to sexuality became more positive, and the proportion reporting a very happy relationship increased. Furthermore, the proportion reporting high satisfaction with sexual activity and that sexuality was an important factor in life increased, whereas those with sexual dysfunctions (erectile dysfunction among men, orgasmic dysfunction in women) decreased. Consistent with population studies of younger samples of later born cohorts ${ }^{1-3}$ the median age of sexual debut decreased and the proportion that had their sexual debut before age 20 increased. The one year prevalence of intercourse in the two earliest birth cohorts was similar to that among septuagenarians reported from studies in the 1950s and 1980s. ${ }^{46}$ The prevalence in the two younger birth cohorts is similar to a European study in $2001-2^{16}$ and a US study in 2005-6. ${ }^{5}$

The main reason for men to cease intercourse was self reported as personal reasons, mirroring reports by women that the reason for cessation of intercourse was due to their partner. Whether elderly couples continue to be sexually active seems to a large extent to be determined by men. ${ }^{17}$ This pattern, which did not change over time, was also reported in studies in the $1950 \mathrm{~s}^{8}$ and in 2005-6. ${ }^{5}$

In agreement with previous reports self reported sexual activity was more common in men, regardless of marital status. ${ }^{56891618-20}$ Differences between the sexes in self reported sexual behaviour, however, decreased from 1971 to 2001 among the 70 year olds in our study. Overall, men reported an earlier age of sexual debut and a higher proportion of premarital sex than women in the 1970s, but this sex difference diminished among those in later born samples. Recent studies on adolescents report that women experience first sexual intercourse at a younger age than men. ${ }^{1-3}$ Finally, whereas 70 year old men in the 1970s more often reported positive attitudes to sexuality than women, there were no sex differences in attitudes in 2000-1. Thus attitudes to sexuality cannot entirely explain observed differences between the sexes in sexual activity. Women were less likely to be married or in other intimate relationships than men, as reported by others. ${ }^{5}$ As in other studies, ${ }^{568}$ the proportion of elderly

Table 3| Self reported sexual behaviour and attitudes in four samples of 70 year olds from Gothenburg, Sweden, examined in 1971-2,1976-7,1992-3, and 2000-1. Values are number who answered question of total number examined (percentage) unless stated otherwise

\begin{tabular}{|c|c|c|c|c|c|c|c|c|c|}
\hline \multirow[b]{2}{*}{ Variable } & \multicolumn{4}{|c|}{ Men } & \multicolumn{5}{|c|}{ Women } \\
\hline & $\begin{array}{l}1971-2 \\
(n=161)\end{array}$ & $\begin{array}{l}1976-7 \\
(n=174)\end{array}$ & $\begin{array}{c}2000 \\
(n=225)\end{array}$ & $\begin{array}{l}\text { Sample trend } \\
\text { P value } \dagger\end{array}$ & $\begin{array}{l}1971-2 \\
(n=221)\end{array}$ & $\begin{array}{l}1976-7 \\
(n=222)\end{array}$ & $\begin{array}{c}1992 \\
(n=241)\end{array}$ & $\begin{array}{c}2000 \\
(n=262)\end{array}$ & $\begin{array}{l}\text { Sample trend } \\
\text { P value } \dagger\end{array}$ \\
\hline $\begin{array}{l}\text { Positive attitude towards } \\
\text { sexuality in old age }\end{array}$ & $121 / 148(82)$ & $139 / 173(80)$ & $200 / 207$ (97) & 0 & $135 / 208(65)$ & $135 / 215(63)$ & $212 / 238(89)$ & $219 / 232(94)$ & 0 \\
\hline Married or cohabiting & $97 / 117(83)$ & $106 / 133(80)$ & $162 / 168(96)$ & 0 & $62 / 89(70)^{\star}$ & $55 / 92(60)^{\star \star}$ & $119 / 135(88)$ & $109 / 117(93)$ & 0 \\
\hline Not married & $24 / 31(77)$ & $33 / 40(83)$ & $38 / 39(97)$ & 0.010 & $73 / 119(61)$ & $80 / 123(65)^{\star}$ & 93/104 (89) & $110 / 115(96)$ & 0 \\
\hline Sexuality a positive factor in life & - & $44 / 174(26)$ & $196 / 206(95)$ & $0 \ddagger$ & - & $10 / 214(5)^{\star \star \star}$ & $121 / 225(54)$ & $\underset{\star 181 / 231(78)}{* \star}$ & 0 \\
\hline $\begin{array}{l}\text { Sexual intercourse during past } \\
\text { year }\end{array}$ & $72 / 152(47)$ & $83 / 173(48)$ & $133 / 203(66)$ & & $35 / 209(12)$ & $39 / 213$ (18) & $81 / 232(35)$ & $77 / 225(34)$ & \\
\hline Married or cohabiting & $62 / 119(52)^{\star}$ & $71 / 133(53)^{\star}$ & $113 / 166(68)$ & 0.002 & $34 / 89(38)^{\star \star \star}$ & $34 / 92(37)^{\star \star \star}$ & $\underset{\star \star \star \star}{70 / 130}(54)$ & $\underset{* \star \star}{63 / 112(56)}$ & 0 \\
\hline Not married & $10 / 33(30)$ & $12 / 40(30)$ & $20 / 37(54)$ & 0.016 & $1 / 120(1)^{\star \star \star}$ & $5 / 121(4)^{\star \star \star}$ & $11 / 102(11)$ & $\underset{\star \star \star \star}{14 / 113(12)}$ & 0 \\
\hline $\begin{array}{l}\text { Sexual intercourse once weekly } \\
\text { or more among sexually active }\end{array}$ & $7 / 72(10)$ & $22 / 83(27)$ & $41 / 133(31)$ & 0.006 & $3 / 35(9)$ & $7 / 39$ (18) & $16 / 81(20)$ & $20 / 77(26)$ & 0.047 \\
\hline $\begin{array}{l}\text { Sexual debut before age } 20 \\
\text { (median age at sexual debut) }\end{array}$ & $\begin{array}{c}77 / 148(52) \\
(19.3)\end{array}$ & $\begin{array}{c}94 / 167(56) \\
(18.7)\end{array}$ & $\begin{array}{c}159 / 207(77) \\
(17.7)\end{array}$ & $0 \S$ & $\begin{array}{l}39 / 203(19) \\
(22.7)\end{array}$ & $\begin{array}{c}57 / 206(28) \\
(22.0)\end{array}$ & $\begin{array}{c}112 / 230(49) \\
(19.6)\end{array}$ & $\begin{array}{c}147 / 229(64) \\
(18.6)\end{array}$ & $0 \S$ \\
\hline $\begin{array}{l}\text { Sexual intercourse before } \\
\text { marriage }\end{array}$ & $123 / 149(83)$ & $147 / 171(86)$ & $183 / 207(88)$ & 0.151 & $\underset{\star \star \star \star}{86 / 180(48)}$ & $\underset{\star \star}{143 / 194}(74)$ & $172 / 229(75)$ & $198 / 226(88)$ & 0 \\
\hline Sexually inexperienced & $1 / 156(1)$ & $0 / 173(0)$ & $0 / 207(0)$ & 0.308 & $\underset{\star \star \star}{23 / 210}(11)$ & $15 / 212(7)^{\star \star \star}$ & $1 / 231(0.4)$ & $1 / 229(0.4)$ & 0 \\
\hline
\end{tabular}

Number of participants varies within cohorts as some declined to answer some questions.

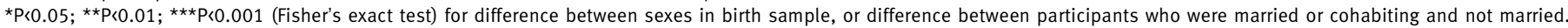

†Cochran-Armitage $x^{2}$ test for sample trend.

$\ddagger$ Fisher's exact test.

$\S$ Test for column trend with asymptotic permutation test of trends. 
people reporting sexual activity was higher among married participants than among unmarried participants, especially in women. Sexual activity was reportedly rare among unmarried women in the 1970s.

In 2000 around two thirds of men and women reported high sexual satisfaction, a substantial increase from 1976, especially in women. The proportion of women who reported no or low satisfaction decreased, whereas the proportion of men with low satisfaction increased. It could be speculated that it has become more permissible for men to admit failure in sexual matters or that a real difference exists. The percentage of men reporting erectile dysfunction decreased during the study period. We have no data to examine whether the advent of new drugs in 1998 to treat erectile dysfunction may have contributed to this phenomenon. Premature ejaculation is one of the most common sexual dysfunctions among men aged 40$80 .{ }^{16}$ The prevalence of premature ejaculation in our study was relatively low. This is in line with observations that the proportion of men with premature ejaculation decreases with age. ${ }^{21}$ The proportion of women reporting anorgasmia decreased, which may further support a better quality of sexual interactions in later born cohorts. Our results for sexual problems are lower than those reported in a US study, ${ }^{5}$ despite a similar prevalence of sexual intercourse in the studies.

It was beyond the scope of this study to examine in detail the reasons for self reported secular changes in sexual behaviour over 30 years. It could be speculated that the changes reflect higher educational levels and better socioeconomic status in the later birth cohorts. Furthermore, cohabiting and living apart became more common. The proportion never married decreased and the proportion divorced increased in the later born samples. The later born samples also experienced better general physical health, ${ }^{22}$ possibly reflected by an increasing average life expectancy in Sweden during the study period ( 72.2 to 77.4 in men, 78.1 to 82 in women). ${ }^{23}$ When several of these factors were taken into consideration in a logistic regression analysis, birth year was still related to sexual activity, suggesting that several yet unidentified factors might be important. Other factors that may have influenced public attitudes to sexuality during the 20th century relate to changes in legislation. For example, between 1911 and 1938 Swedish law prohibited information about and the sale of contraceptive devices. In 1946, pharmacies were required to sell contraceptives (condoms and diaphragms) to anyone requesting them; however, homosexuality was still prohibited until 1949. General sex education became compulsory in elementary schools in Sweden in 1955. By the end of the 1950s condoms were available in vending machines in public places. The "sexual revolution" followed in the 1960s, with the contraceptive pill and, later on, intrauterine devices. ${ }^{24}$

\section{Strengths and limitations}

Major strengths of this study are that it is based on four general population samples examined using identical methods over a 30 year period, and that the interviews were part of a comprehensive investigation on ageing and people were not recruited explicitly to talk about their sexuality. Furthermore, the interviews were carried out by doctors and nurses experienced in asking sensitive questions.

Despite the strengths of the study, possible limitations need to be mentioned. Firstly, although the response rate in this sample is higher than in most studies on sexual behaviour, it did decline from $80 \%$ in the first sample to $65 \%$ in the fourth sample. Comparisons between responders and non-responders identified no differences for several factors, including three year mortality rate, indicating that non-responders were similar to responders. Furthermore, the secular trends in reported sexual behaviour over the 30 year study period were so pronounced that declining response rates could not explain the differences between the samples of 70 year olds. We cannot, however, exclude the possibility that those who declined had more sexual problems than those who participated. Secondly, studies of elderly people include a survival bias-we examined only those who reached age 70 . Thus we cannot draw any conclusions on sexual behaviour before this age. Thirdly, sexual behaviour is a sensitive matter to report to strangers. Semistructured interviews were, however, done by

Table 4 | Sexual satisfaction and function among sexually active 70 year olds from Gothenburg, Sweden, examined in 1971-2, 1976-7, $1992-3$, and 2000-1. Values are number who answered question of total number examined (percentage) unless stated otherwise

\begin{tabular}{|c|c|c|c|c|c|c|c|}
\hline \multirow[b]{2}{*}{ Variable } & \multicolumn{3}{|c|}{ Men } & \multicolumn{4}{|c|}{ Women } \\
\hline & $1976-7$ & $2000-1$ & $\begin{array}{c}\text { Sample difference } \\
\text { P value } \dagger\end{array}$ & $1976-7$ & $1992-3$ & 2000 & $\begin{array}{l}\text { Sample trend } \\
\text { Pvalue }^{\star}\end{array}$ \\
\hline High satisfaction & $48 / 83(58)$ & $94 / 132(71)$ & 0.054 & $16 / 39(41)$ & $38 / 80(48)$ & $45 / 73(62)$ & 0.039 \\
\hline Low or no satisfaction & $2 / 83(2)$ & 11/132 (8) & 0.086 & $15 / 39(39)^{\star \star \star}$ & $12 / 80(15)$ & $7 / 73(10)$ & 0 \\
\hline Erectile dysfunction & $15 / 83(18)$ & 11/133 (8) & 0.051 & - & - & - & - \\
\hline Ejaculation dysfunction & $4 / 83(5)$ & $16 / 133(12)$ & 0.092 & - & - & - & - \\
\hline Premature ejaculation & $3 / 83(4)$ & $5 / 133(4)$ & 1.000 & - & - & - & - \\
\hline Always or usually orgasm & - & - & - & $23 / 39(59)$ & 44/81 (54) & $58 / 70(83)$ & 0.015 \\
\hline Never had orgasms & - & - & - & $16 / 39(41)$ & $20 / 81(25)$ & $4 / 70(6)$ & 0 \\
\hline
\end{tabular}

$\star \star \star P<0.001$ (Fisher's exact test) for difference between sexes in birth sample.

${ }^{\star}$ Cochran-Armitage $x^{2}$ test for sample trends.

†Fisher's exact test. 


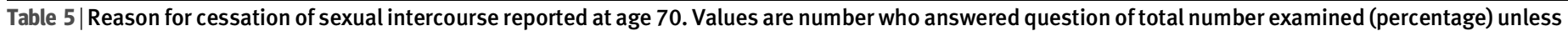
stated otherwise

\begin{tabular}{|c|c|c|c|c|c|c|c|}
\hline \multirow[b]{2}{*}{ Variable } & \multicolumn{3}{|c|}{ Men } & \multicolumn{4}{|c|}{ Women } \\
\hline & $1976-7$ & $2000-1$ & $\begin{array}{c}\text { Sample difference } \\
\text { P value } †\end{array}$ & $1976-7$ & $1992-3$ & $2000-1$ & $\begin{array}{c}\text { Sample trend } \\
\text { P value* }\end{array}$ \\
\hline No partner & $11 / 89(12)$ & 4/67 (6) & 0.272 & $60 / 158(38)^{\star \star \star}$ & $47 / 136(35)$ & $56 / 146(38)^{\star \star \star}$ & 0.936 \\
\hline $\begin{array}{l}\text { Partner's illness, loss of } \\
\text { desire or capability }\end{array}$ & $21 / 89(24)$ & $20 / 67(30)$ & 0.462 & $61 / 158(39)^{\star}$ & $57 / 136(42)$ & $61 / 146(42)$ & 0.533 \\
\hline $\begin{array}{l}\text { Own illness, loss of } \\
\text { desire or capability }\end{array}$ & $57 / 89(64)$ & $43 / 67(64)$ & 1.000 & $37 / 158(23)^{\star \star \star}$ & $32 / 136(24)$ & $29 / 146(20)^{\star \star \star}$ & 0.520 \\
\hline
\end{tabular}

***P<0.001 (Fisher's exact test) for difference between the sexes within birth sample.

${ }^{*}$ Cochran-Armitage $x^{2}$ test for sample trends.

†Fisher's exact test.

doctors or experienced psychiatric research nurses. It might be easier to report sexual behaviour to a professional within the context of an examination on different aspects of ageing. Most reports indicate that people are reasonably open about their sexual behaviour when the observer is objective and comfortable with the topic of inquiry. ${ }^{7}$ In line with this, the Duke studies ${ }^{7}$ reported a high correlation among married couples regarding answers on the frequency of sexual intercourse. Fourthly, the first three cohorts were examined by psychiatrists and the fourth by psychiatric research nurses. The large differences in results were, however, observed between the first two and the latest two cohorts, not between those examined by psychiatrists and research nurses. Fifthly, changes in evaluations of responses over time may have influenced the results. One researcher (IS) was trained by those who carried out the examinations in the $1970 \mathrm{~s}$, who in turn trained those doing the examinations in 1992 and 2000. Inter-rater reliability between the researcher and examiners in the 1970s and 1990s was high, ensuring consistency in the interviews over time. Sixthly, the study is based on self report, which lends itself to reporting bias. Two qualitative studies indicated that participants from later born cohorts reported that they had learnt to speak more openly about sexuality ${ }^{25}$ and that many welcomed the opportunity to talk about sex and discuss issues they had never talked about before. ${ }^{26}$ More positive attitudes to sexuality in 70 year olds in later born cohorts might have resulted in more participants reporting sexual intercourse. Changing attitudes affect both interviewers and participants. It is possible that our results reflect a more open minded attitude in society to sexual matters rather than real

\section{WHAT IS ALREADY KNOWN ON THIS TOPIC}

Secular trends in elderly people's sexual behaviour is unclear

\section{WHAT THIS STUDY ADDS}

The quantity and quality of sexual experiences among

70 year olds in Sweden improved over a 30 year period

Attitudes to sexuality have become more positive in this age group changes in sexual behaviour. Seventhly, the definition of sexual activity was limited to intercourse between heterosexuals. Questions on homosexual behaviour and masturbation were included in the original study but then withdrawn in 1976-7, as they evoked strong reactions and many refused to respond to the questions. Thus we cannot generalise our results to other types of sexuality than intercourse between heterosexuals. As we aimed to describe secular trends, we were limited to those questions used in the 1970s. Finally, depression is common in elderly people and is well known to affect sexual activity. Our results for prevalence, however, did not change when we excluded depressed participants, and year of birth was still related to sexual activity in 70 year olds when depression was controlled for in logistic regression analyses including all four samples.

\section{Conclusions}

Self reported quantity and quality of sexual experiences among 70 year olds improved over a 30 year period. At the same time, a relatively large proportion of participants had ceased having intercourse. Our study, however, shows that most elderly people consider sexual activity and associated feelings a natural part of later life. It is thus important that sexuality is taken into consideration when dealing with elderly people.

Contributors: NB drafted and critically revised the manuscript and analysed and interpreted the data. MW and DG critically revised the manuscript and analysed and interpreted the data. IS was responsible for funding and supervision, drafted and critically revised the manuscript, analysed and interpreted the data, and was responsible for planning the study and data collection. He is guarantor for the paper.

Funding: This study was supported by grants from the Swedish Council for Working Life and Social Research (No 2001-2835, 2001-2646, 2003 0234, 2004-0150, 2004-0145, 2006-0596, and 2006-0020), the Alzheimer's Association Stephanie B Overstreet Scholars (IIRG-00-2159), the Swedish Research Council (No 11267, 2005-8460, and 825-20077462), the Bank of Sweden Tercentary Foundation, Stiftelsen för Gamla Tjänarinnor, and Handlanden Hjalmar Svenssons Forskningsfond. The sponsors had no role in the study design, data collection, data analyses, the interpretation of data, the writing of the report, or the decision to submit the article for publication.

Competing interests: None declared.

Ethical approval: This study was approved by the ethics committee for medical research at Gothenburg University.

Provenance and peer review: Not commissioned; externally peer reviewed. 
1 Turner CF, Danella RD, Rogers SM. Sexual behavior in the United States 1930-1990: trends and methodological problems. Sex Transm Dis 1995;22:173-90.

2 Lewin B, Fugl-Meyer K, Helmius G, Lalos A, Månsson S, the National Institute of Public Health. Sexuality in Sweden: about sex life in Sweden 1996. 3rd ed. Stockholm: National Institute of Public Health, 1998. (Swedish language.)

3 Caron SL, Moskey EG. Changes over time in teenage sexual relationships: comparing the high school class of 1950, 1975, and 2000. Adolescence 2002;37:515-26.

4 George LK, Weiler SJ. Sexuality in middle and late life. The effects of age, cohort, and gender. Arch Gen Psychiatry 1981;38:919-23.

5 Lindau ST, Schumm LP, Laumann EO, Levinson W, O'Muircheartaigh CA, Waite LJ. A study of sexuality and health among older adults in the United States. N Engl I Med 2007;357:762-74.

6 Diokno AC, Brown MB, Herzog AR. Sexual function in the elderly. Arch Intern Med 1990;150:197-200.

7 Pfeiffer E, Verwoerdt A, Wang HS. Sexual behavior in aged men and women. I. Observations on 254 community volunteers. Arch Gen Psychiatry 1968;19:753-8.

8 Verwoerdt A, Pfeiffer E, Wang HS. Sexual behavior in senescence. Changes in sexual activity and interest of aging men and women.J Geriatr Psychiatry 1969;2:163-80.

9 Verwoerdt A, Pfeiffer E, Wang HS. Sexual behavior in senescence. II. Patterns of sexual activity and interest. Geriatrics 1969;24:137-54.

10 Rinder L, Roupe S, Steen B, Svanborg A. Seventy-year-old people in Gothenburg. A population study in an industrialized Swedish city. Acta Med Scand 1975;198:397-407.

11 Persson G. Sexuality in a 70-year-old urban population. J Psychosom Res 1980;24:335-42.

12 Nilsson LV. Prevalence of mental disorder in a 70-year-old urban sample. A cohort comparison. J Clin Exp Gerontol 1983;5:101-20.

13 American Psychiatric Association. Diagnostic and statistical manual of mental disorders, 3rd ed, revised. Washington DC: APA, 1987.

14 Skoog I, Nilsson L, Landahl S, Steen B. Mental disorders and the use of psychotropic drugs in an 85-year-old urban population. Int Psychogeriatr 1993;5:33-48.
15 Skoog I, Nilsson L, Palmertz B, Andreasson LA, Svanborg A. A population-based study of dementia in 85-year-olds. N Engl / Med 1993;328:153-8.

16 Nicolosi A, Buvat J, Glasser DB, Hartmann U, Laumann EO, Gingell C. Sexual behaviour, sexual dysfunctions and related help seeking patterns in middle-aged and elderly Europeans: the global study of sexual attitudes and behaviors. World J Urol 2006;24:423-8.

17 Laumann EO, Nicolosi A, Glasser DB, Paik A, Gingell C, Moreira E, et al. Sexual problems among women and men aged $40-80 \mathrm{y}$ : prevalence and correlates identified in the global study of sexual attitudes and behaviors. Int J Impot Res 2005;17:39-57.

18 Pfeiffer E, Davis GC. Determinants of sexual behavior in middle and old age. J Am Geriatr Soc 1972;20:151-8.

19 Kivelä S, Pahkala K, Honkakoski A. Sexual desire, intercourse, and related factors among elderly Finns. Nordisk sexologi 1986:18-27.

20 Pfeiffer E, Verwoerdt A, Wang HS. The natural history of sexual behavior in a biologically advantaged group of aged individuals. I Gerontol 1969;24:193-8.

21 Basile Fasolo C, Mirone V, Gentile V, Parazzini F, Ricci E. Premature ejaculation: prevalence and associated conditions in a sample of 12,558 men attending the andrology prevention week 2001—a study of the Italian Society of Andrology (SIA). J Sex Med 2005;2:376-82.

22 Wilhelmson K, Allebeck P, Steen B. Improved health among 70 year olds: comparison of health indicators in three different birth cohorts. Aging Clin Exp Res 2002;14:361-70.

23 Statistics Sweden. 2008. www.scb.se/templates/ tableOrChart_25830.asp. (Swedish language)

24 Sundström K, the National Institute of Public Health. How do others do? About sexuality and relationship in the 1990s. Stockholm: National Institute of Public Health, 2000. (Swedish language.)

25 Von Sydow K. Female sexuality and historical time: a comparison of sexual biographies of German women born between 1895 and 1936 Arch Sex Behav 1996;25:473-93.

26 Gott M, HinchliffS. How important is sex in later life? The views of older people. Soc Sci Med 2003;56:1617-28.

Accepted: 12 May 2008 